\title{
Smartphones as a Non-Invasive Surveying Tool to Monitor Bats
}

\author{
Amanda-Jean Blackburn ${ }^{1}$ and Shem Unger ${ }^{1 *}$
}

Bats are important keystone species which provide ecosystem services by consuming a variety of insects and agricultural pests. Many native bat species are currently threatened with either habitat loss or emerging infectious diseases, including White Nose Syndrome. Therefore, there is a need to develop survey approaches which increase accessibility to citizen scientists and researchers alike to monitor populations, such as with emerging, affordable smartphone enabled technologies. We assessed the efficacy of a smartphone enabled handheld bat detector (Wildlife Acoustics Echo Meter Touch 2) to record and identify echolocation calls of common bat species on a seminatural area of Wingate Campus, a small university in the Charlotte metropolitan area, North Carolina. We further utilized smartphone technology to record seasonal internal temperature and luminosity fluctuations within deployed bat boxes using HOBO thermo-loggers. Lastly, we used a smartphone enabled WIFI endoscope inspection camera to periodically check occupancy of bat boxes. We identified five species of bats, from 55 recordings during Spring and Fall of 2018 (4/2/2018 to 10/28/2018), including the big brown bat (Eptesicus fuscus), hoary bat (Lasiurus cinereus), Mexican free-tailed bat (Tadarida brasiliensis), silver haired bat (Lasionycteris noctivagans), and northern yellow bat (Lasiurus intermedius) at our study site. Temperature and luminosity of bat boxes varied depending on location (full or partial sun), while the endoscope allowed for non-invasive monitoring of bat boxes, of which none were found to be occupied. The purpose of this study is to use smartphone enabled technology as a non-invasive surveying tool for identification and monitoring of bats.

\section{INTRODUCTION}

Bats play critical roles in many ecosystems by consuming insects potentially harmful to agriculture, dispersing seeds, pollinating, and as bioindicators of environmental change (Jones et al., 2009; 2010; Boyles et al., 2011). Across North America, bats can typically be observed feeding on insects immediately following sundown, as they emerge from their roosts to forage in both urban and forested environments. North Carolina is home to 17 species of bats, four of which are federally listed as endangered or threatened (Caldwell et al., 2017). Although bats are important to many ecosystems, many populations in eastern and western North Carolina are at risk for an emerging fungal disease, White Nose Syndrome (WNS), or Pseudogymnoascus destructans (Turner et al., 2011; Graeter et al., 2015). In addition, bats may be threatened by anthropogenic land use changes and increasing urbanization which may influence the availability of roosting sites (Schimpp et al., 2018). Given these emerging threats, biologists need to further investigate alternative and affordable ways to survey for bats. For example, the possibility of incorporating data collected by citizen scientists, local communities, and students at universities.

Acoustic surveys are the most common method to survey for bats. These surveys rely on the biology of bats, which use ultrason-

'Biology Department, 220 N Camden Rd, Wingate University, Wingate, NC 28174

*To whom correspondence should be addressed:

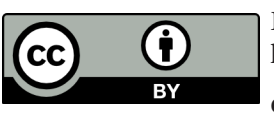

Except where otherwise noted, this work is licensed under https://creativecommons.org/licenses/by/4.0

doi:10.22186/jyi.37.3.24-30 ic calls emitted while foraging for insects (Fenton and Simmons, 2014). As each species has distinct echolocation call morphologies, identification of these calls can be accomplished via standard acoustic monitoring technology and software. Previously, this has been expensive ( $>\$ 5,000$ USD), therefore most citizen scientists would have limited access this technology. In addition, handling of bats for species identification requires permitting by local state and federal agencies, as well as any handler to possess current rabies vaccinations.

Bats are capable of inhabiting a variety of roosting sites in both natural and manmade structures (Kunz and Lumsden, 2003). However, many communities and state parks typically improve available roosting habitats for bats by deploying multi-chambered bat boxes, to create artificial roosting habitats that bats may occupy throughout the year (Tuttle et al., 2013). Occupancy of these bat boxes can be affected by canopy cover, box design, level of human disturbance, and adequate solar exposure (White, 2004, Rueegger et al., 2018). Moreover, not all species are likely to use bat boxes at equal frequencies (Griffiths et al., 2017). However, little attention has been given to more recent methods for either more affordable bat species identification or monitoring of deployed bat boxes using non-invasive smartphone technology. These technologies can help increase the amount of available data on bat species presence and habitat use in urban environments. Smartphones have become increasingly utilized for data collection in environmental sciences by both citizen scientists and researchers (Gutowsky et al., 2013, Frigerio et al., 2018, Stitt et al., 2019), for the identification of flora and fauna incorporating geographic location and pattern recognition applications such as iNaturalist (Nugent, 2018). Several smartphone-based research devices have recently become 
available to researchers and citizen scientists. For example, the Echo Meter Touch bat detector (Wildlife Acoustic) has previously been used by researchers to record bat echolocation calls (Willie et al., 2018), however few studies have reported on its use and application as an affordable, non-invasive monitoring technique in exploratory studies. Endoscopes are an additional wildlife survey technology for assessing occupancy of habitat, i.e. burrows (Parusnath et al., 2017), and now have smartphone compatible models available. These affordable, smartphone-enabled emerging technologies may in time prove to be either an alternative or additional method for monitoring bats and other organisms.

The goal of this study was to survey and monitor bat populations around Wingate University using new smartphone compatible technology. Specifically, we assessed the use of smartphone devices to (1) identify common bat species using the Echo Meter Touch 2 (Wildlife Acoustics), (2) monitor temperature and light in bat boxes placed in either direct or indirect sun using a $\mathrm{HOBO} \otimes$ Pendant ${ }^{\circledR}$ MX2202 data logger, and (3) check for bat box occupancy using a smartphone enabled endoscope. We hypothesize that these various smartphone-enabled devices will allow us to accurately monitor bat populations and habitats. These non-invasive survey tools may provide conservation managers and educators an affordable method for effectively monitoring and researching bats and an avenue for incorporating these techniques into outreach citizen science education programs.

\section{MATERIALS AND METHODS}

\section{Study Site}

Wingate University is a small liberal arts college located in close proximity to the Charlotte metropolitan area of North Carolina, USA. A section of Wingate campus includes a semi-natural area that consists of mixed hardwood forest (including Quercus spp. (oak), Juniperus spp. (cedar), and Loblolly pine trees, Pinus spp.), in addition to several open mowed fields and trails with a small $55,000 \mathrm{~m}^{2}$ man-made university lake (Figure 1). This area, was selected as an ideal location to monitor bats and deploy bat boxes, based on previous visual observation of bat activity at the site, including emerging and foraging bats.

\section{Bat Box Deployment and Monitoring}

We monitored bats on Wingate Campus from April to October of 2018. On April 5, 2018 two bat boxes (one single chambered and one triple chambered, Bat Conservation International; BB1 \& BB2) were deployed around Wingate University Campus Lake (Figure 1), at a height of 6 meters attached to a tree to allow bats to drop down an adequate distance when emerging to forage (Tuttle, 2013). Bat boxes were painted prior to deployment with brown, non-gloss outdoor paint to increase heat absorbance. The locations were selected based on proximity to a water source (within 300 meters) and range of ideal sunlight the location received daily (Tuttle, 2013). For example, we deployed a triple chamber Bat box 1 (BB1), in full direct sun within $300 \mathrm{~m}$ a small pond and bat box 2 (BB2), a single chamber box placed in only partial sun near the lake for comparison (Figure 1). Each bat box was fitted with a

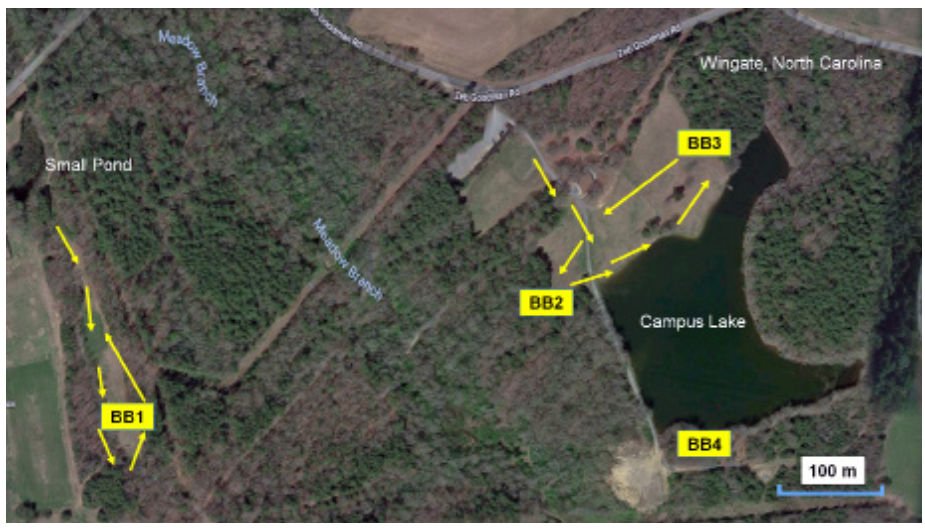

Figure 1. Google Earth map of study area on Wingate University Campus Lake. This site is a mixture of hardwood forest, open mowed grassy fields, and trails. Areas of bat box deployment Bat boxes 1, 2, 3, and 4 (BB1, BB2, BB3, and BB4) shown in yellow boxes with arrows indicating survey location of call recording. $\mathrm{BB} 1$ and $\mathrm{BB} 2$ included temperature loggers and were suspended 20 feet on trees with BB1 in full sun and BB2 in partial sun. BB3 and BB4 were in full sun but were not utilized for temperature data. Google map data retrieved 11/2/2018, https://www. google.com/maps/@34.9865251,-80.4310875,639m/data=!3m1!1e3.
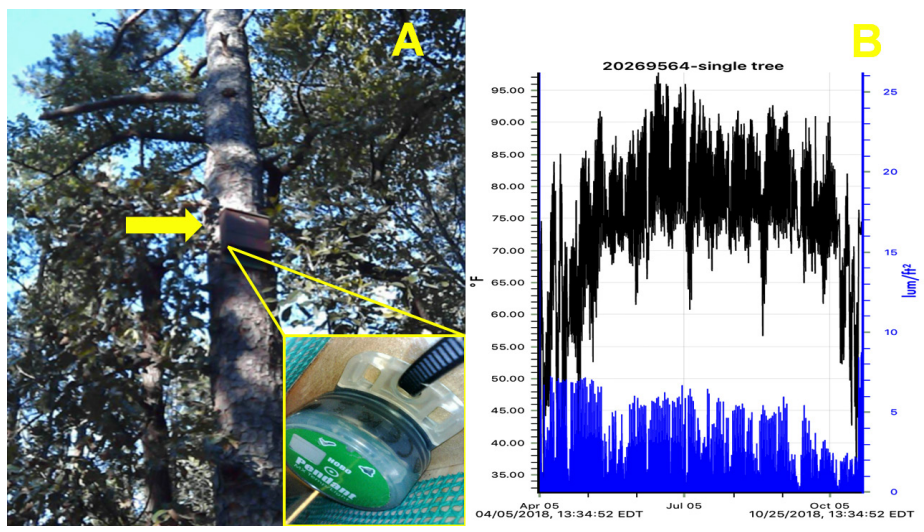

Figure 2. Bat Box 1 deployed (BB1) showing placement of HOBO® Pendant MX2202 temperature and luminosity logger (A), and preliminary downloaded data screen using WIFI (B). Data loggers were attached internally with zip ties to record ambient temperature and light (luminosity) every hour.

HOBO ${ }^{\circledR}$ Pendant ${ }^{\circledR}$ MX2202 logger to simultaneously record both temperature and light luminosity hourly ( 24 data points per day; Figure 2). Data loggers were calibrated to record data at the same time, to allow for comparisons between light and temperature for BB1 and BB2. We downloaded temperature and light luminosity data on October 25, 2018 using the Bluetooth HOBOmobile application. This data is exported as an excel, CSV, TEXT, or HOBO file formats. The data was downloaded to the author's smartphone within 5-10 seconds as the smartphone was within a $\sim 6$ meters radius. In addition, on February 9, 2018, we deployed four bat boxes on two $1.2 \mathrm{~m}$ by $1.2 \mathrm{~m}$ poles, each with one single chamber and one triple chamber from Bat Conservation International (BB3, BB4), at a height of 6 meters in full sun surrounding the lake. 

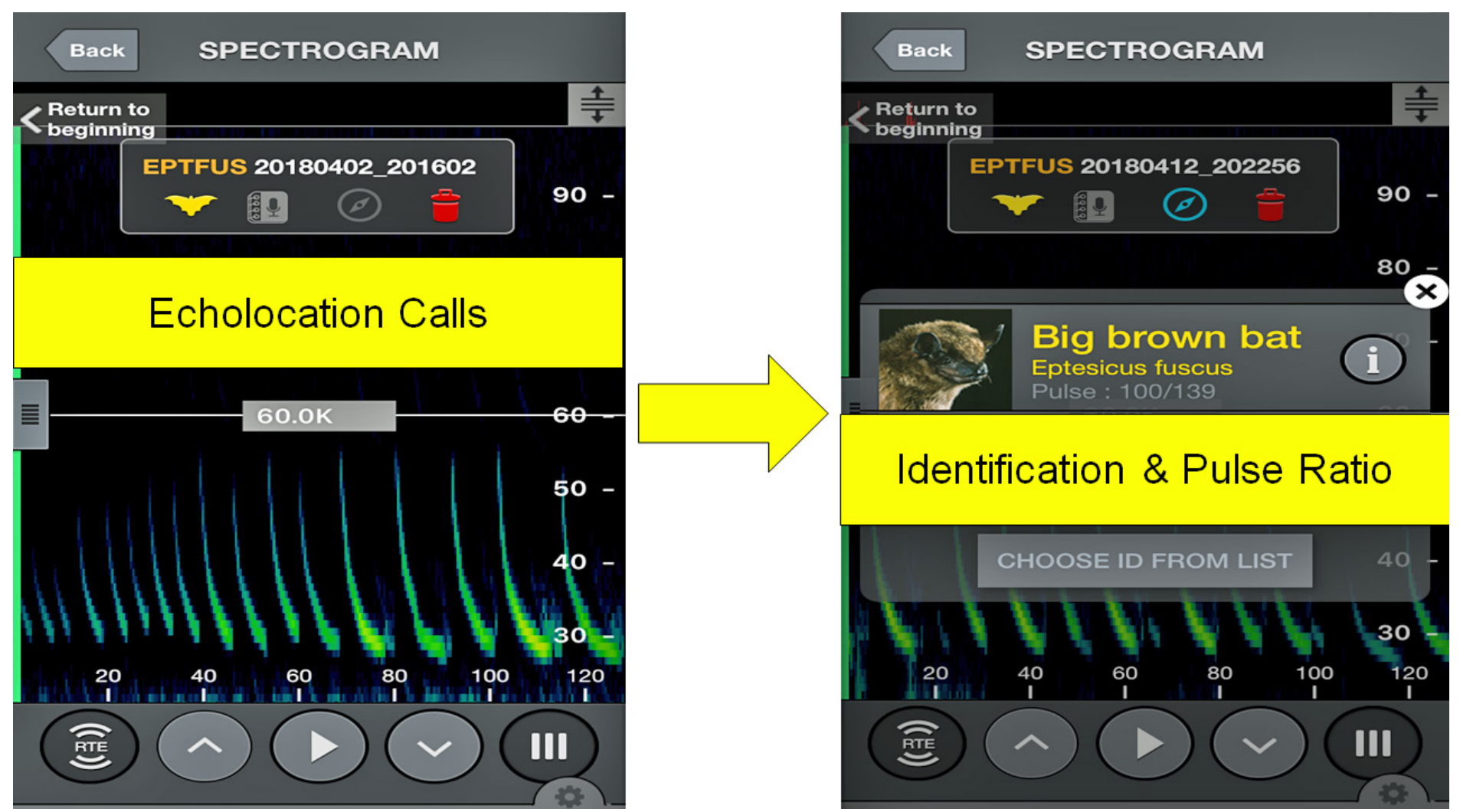

\section{Identification \& Pulse Ratio}

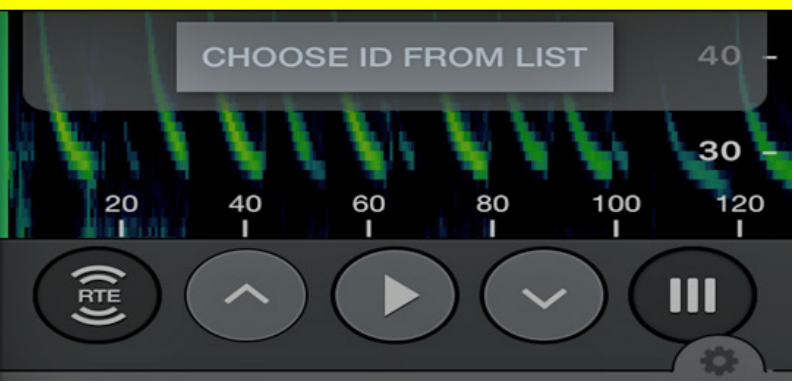

Figure 3. Echo Meter Touch 2 (Wildlife Acoustics) workspace screenshot. Bat echolocation calls are shown with peaks below $60 \mathrm{Khz}$ (left) and identification and pulse ratio shown with bat species identification (right).

Fall Bat Box 1

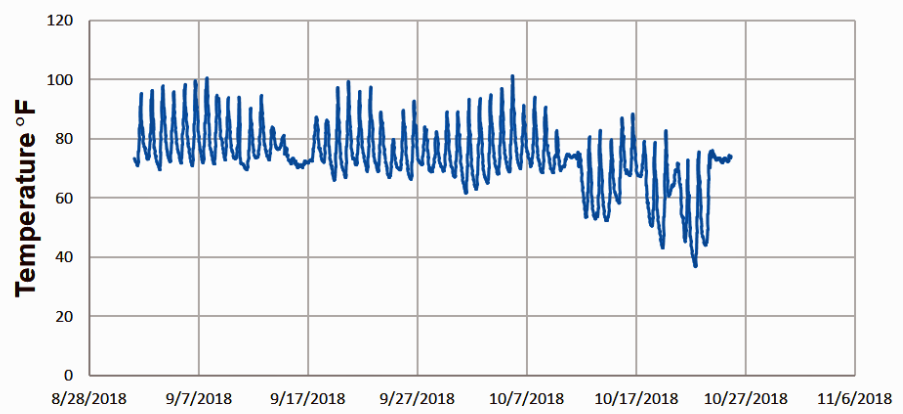

Time

Fall Bat Box 2

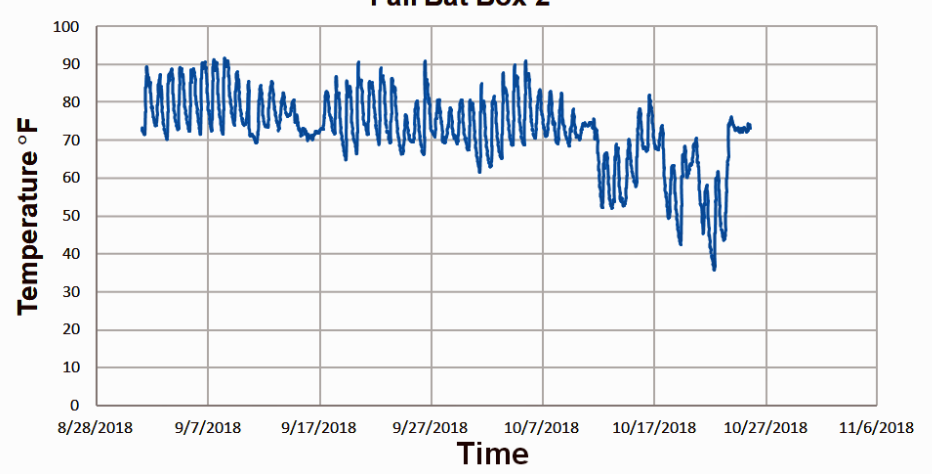

Spring Bat Box 1

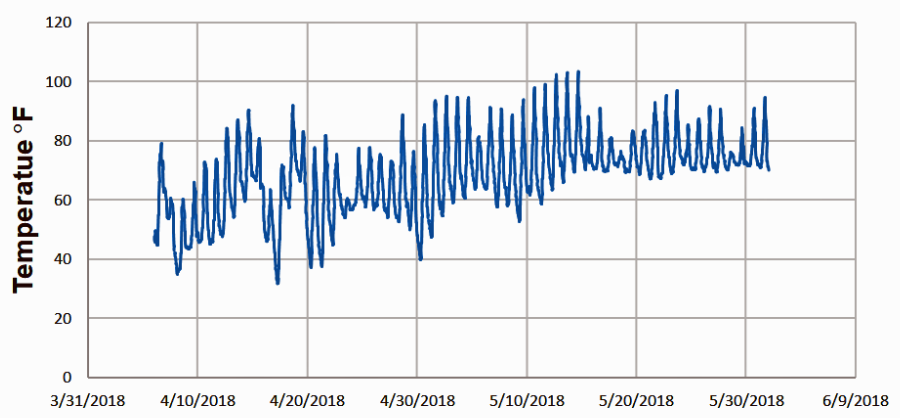

Time

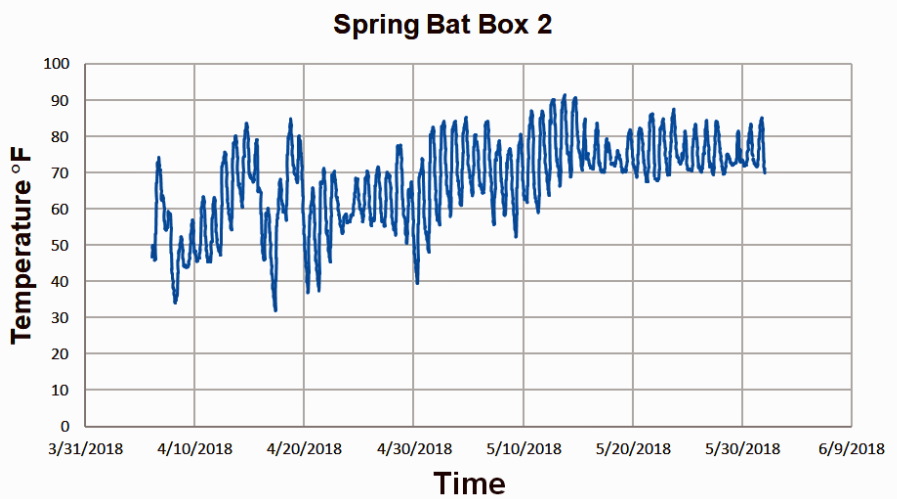

Figure 4. Temperatures of Bat Box 1 (top) and Bat Box 2 (bottom) for Fall and Spring. Temperatures were recorded and downloaded from HOBO ${ }^{\circledR}$ Pendant MX2202 temperature and luminosity loggers. 


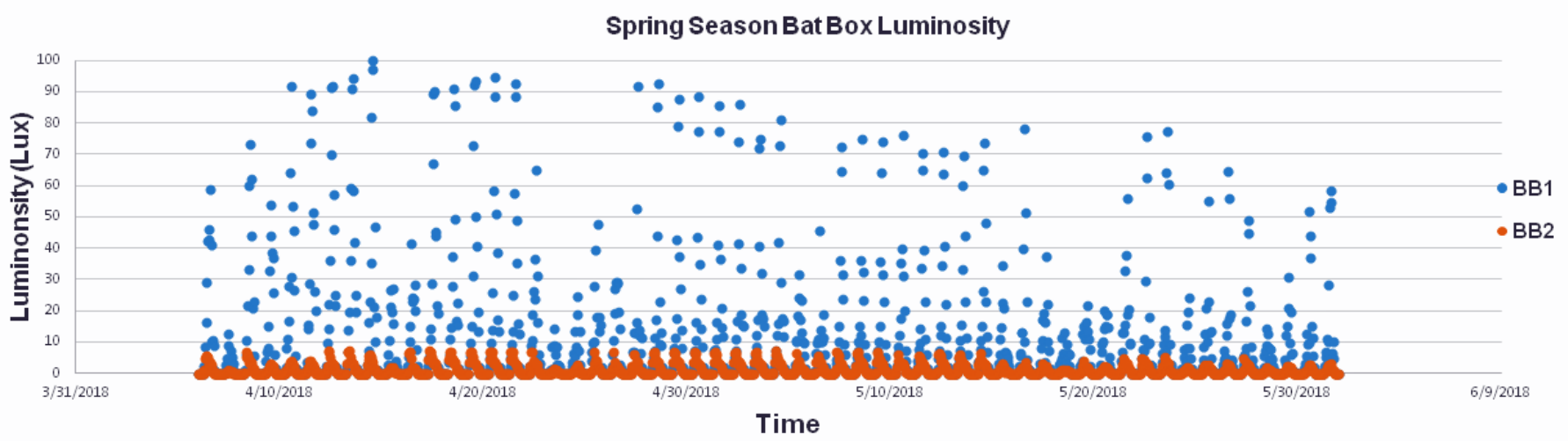

Fall Season Bat Box Luminosity

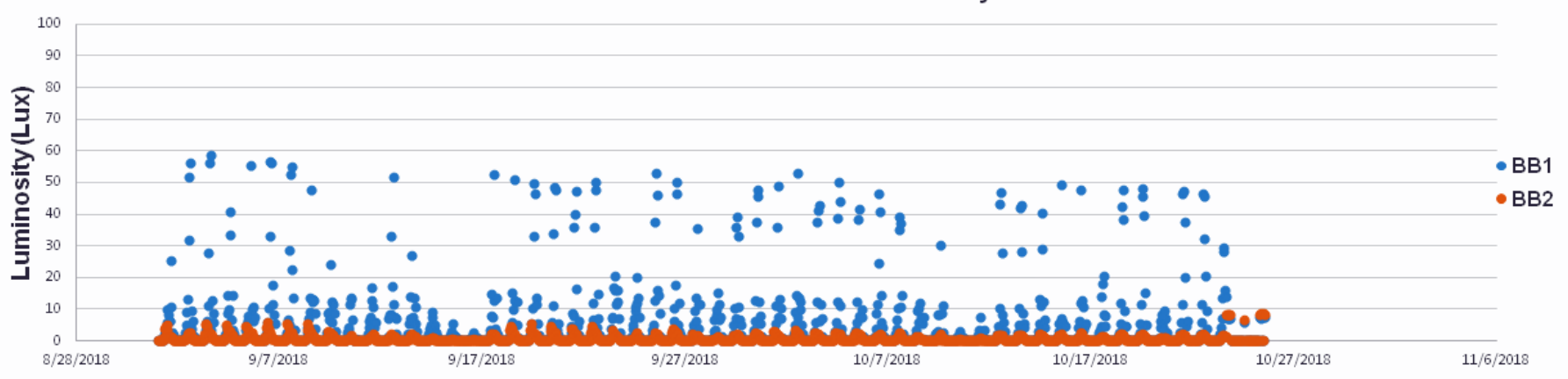

Time

Figure 5. Luminosity values for Spring (A) and Fall Seasons (B) for Bat Box 1 and Bat Box 2. Luminosity values are shown from $H O B O \circledR$ Pendant MX2202 temperature and luminosity loggers. Bat box 1 represented by BB1 and bat box 2 represented by BB2.

These bat boxes were used primarily to examine occupancy (if bats were present) in addition to other bat boxes with temperature loggers. Finally, we used a smartphone enabled endoscope camera (a YPC110 Leadnovo ${ }^{\circledR}$ wireless endoscope inspection camera equipped with an $8 \mathrm{~mm}$ waterproof LED lens, semi-rigid cable, and WIFI) monthly to determine whether bat boxes were occupied and if so by how many bats.

\section{Bat Species Identification}

A Wildlife Acoustics Echo Meter Touch 2 and related smartphone application was used to listen, record, and identify bats while in flight at our study site on Wingate University (Figure 3). This ultrasonic module and application transforms the sound data into audio that humans can hear in real time and allows the user to identify various bat species by their call without handling individuals. Bat calls enter the module through the acoustical horn, designed to reduce unwanted echoes. The horn directs the sound into the module's microphone, capturing frequencies up to $192 \mathrm{k}$ Hz. The Wildlife Acoustics application allows recording and automatic identification of echolocation calls, using the Auto ID Selection tab, North American database with 16 possible species found in North Carolina. All recorded calls were analyzed for total call length in seconds, pulse ratio (percentage of individual calls or pulses positively used to identify species), time, GPS location, and date of echolocation recordings. To ensure quality control, all recorded calls were manually examined to ensure recording peaks were consistent with bat echolocation calls, and minimal peaks from ambient noise were not present which could result in a false identification. In addition, we excluded any echolocation recordings with low pulse ratios (below $\sim 50 \%$ ), to increase likelihood of echolocation call identification, as low pulse ratios indicate low numbers of calls were used for species identification, indicating either potentially low quality recordings or high distance of bat to observer. We also excluded any potentially spurious species identification, species observed less than three separate sampling occasions. Bats were surveyed twice a week, from April-May and September-October by walking a 15 minute loop in an open clearing near deployed bat boxes (BB1 \& BB2 areas, Figure 1). All acoustic surveys occurred 30 minutes before and after sunset, when individual bats were visibly seen by authors active in flight. Lastly, to inform bat call recordings, we obtained wind $(\mathrm{mph})$ and ambient temperature data $\left({ }^{\circ} \mathrm{F}\right)$ collected from the AccuWeather website (AccuWeather) for each day that bat calls were recorded. We ran a Pearson Correlation Coefficient between the number of bats identified and temperature, as well as the number of bats identified and wind speed. To compare bat box temperature and luminosity, we ran a t test for $\mathrm{BB} 1$ and $\mathrm{BB} 2$ for both fall and spring temperatures (Fall: $9 / 1 / 18$ to $10 / 25 / 18$; Spring: 4/6/18 to $5 / 31 / 18$ ).

\section{RESULTS}

We noted fluctuations in temperature between the spring and fall data for BB1 and BB2 (Figure 4). We noted a variation of $\sim 0.5$ to 
RELATIVE ABUNDANCE OF BAT SPECIES IDENTIFIED

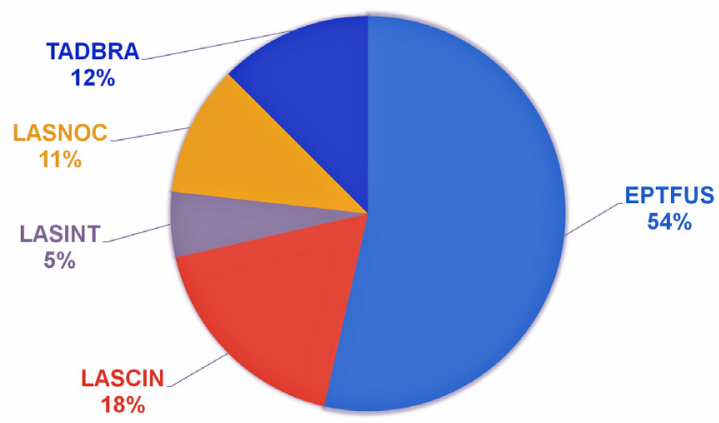

Figure 6. Relative abundance of bat species identified during the study by the Echo Meter Touch 2. Species identified shown as standard bat identification codes. Codes indicating species are as follows: EPTFUS (Big brown bat), LASCIN (Hoary bat), TADBRA (Mexican free-tailed bat), LASNOC (Silver-haired bat), and LASINT (Northern yellow bat). Note EPTFUS, or Big brown bat is the most common species identified in the Wingate University Campus Lake area.

$\sim 5^{\circ} \mathrm{F}$ in daily temperature values during certain times of the day, however mean temperatures for spring and fall BB1 were 68.1 and $73.6^{\circ} \mathrm{F}$, while spring and fall $\mathrm{BB} 2$ temperature was 67.7 and $72.9^{\circ} \mathrm{F}$, respectively. We did not find significant differences between $\mathrm{BB} 1$ and BB2 for either spring or fall temperatures, $t(499)=-0.973, p$ $=0.165$, and $t(499)=-0.612, p=0.268$, respectively. Temperatures recorded during both spring and fall seasons followed seasonal fluctuations representing ambient temperature, with spring temperature increasing over time and fall temperatures decreasing over time. Temperature fluctuations remained consistent in the fall until the second week of October and in the spring until the third week of May 2018. Luminosity values (amount of light penetrating bat boxes measured in lux (1 lumen per square meter) for the spring were higher than the luminosity values for the fall (Figure 5). Mean lux for $\mathrm{BB} 1$ and $\mathrm{BB} 2$ in the spring were 11 and 1 respectively, while mean lux for $\mathrm{BB} 1$ and $\mathrm{BB} 2$ for the fall were 5 and 1 respectively. As expected, we found significant differences between BB1 and BB2 for both spring and fall luminosity, $t=11.767$, $p<0.0001$, and $t=9.12, p<0.0001$, respectively. This showed that the luminosity was significantly higher in BB1 deployed in full sun, compared to BB2, deployed in partial shade. While we detected several bat species in close proximity to our deployed bat boxes using the bat detector, using the smartphone endoscope we found no individual bats occupying any bat box during our study.

Acoustic Surveys using the Wildlife Acoustics Echo Meter Touch 2 positively identified 5 species of bats from a total of 55 detections occupying Wingate University Campus Lake. These were observed at different relative abundances (Figure 6). These include the big brown bat, Eptesicus fuscus, hoary bat, Lasiurus cinereus, Mexican free-tailed bat, Tadarida brasiliensis, silverhaired bat, Lasionycteris noctivagans, and northern yellow bat, Lasiurus intermedius (Table 1). All identified bats echolocation frequencies were found to be within expected ranges, i.e., Eptesi-
Table 1. Bat Species identified using the Echo Meter Touch 2 application (Wildlife Acoustics) on Wingate Campus. Included are species code, species, common name, number of detections, average call length, and pulse ratio percentages. All species were sampled during surveys of Wingate Campus area.

\begin{tabular}{ccccc}
\hline Common Name & Species ID & $\begin{array}{c}\text { Total } \\
\text { Detections }(\#)\end{array}$ & $\begin{array}{c}\text { Cell Length } \\
\text { Average }(s)\end{array}$ & $\begin{array}{c}\text { Pulse Ratio } \\
\text { Average (\%) }\end{array}$ \\
\hline Big Brown Bat & EPTFUS & 30 & 12.9 & 71.1 \\
Hoary Bat & LASCIN & 10 & 8.1 & 82.4 \\
Mexican Free-tailed Bat & TADBRA & 6 & 13.0 & 55.4 \\
Silver-haired Bat & LASNOC & 6 & 13.5 & 69.4 \\
Northern Yellow Bat & LASINT & 3 & 11.0 & 61.1 \\
\hline
\end{tabular}

cus fuscus (25-51 kHz), Lasiurus cinereus (21-32 kHz), Tadarida brasiliensis (24-48 kHz), Lasionycteris noctivagans (26-38 kHz), and Lasiurus intermedius (29-41 kHz; Williams et al., 2002). The pulse ratio average (percentage of calls identified to species) and the average call length in seconds $(s)$ varied across species (Table 1). Most echolocation call peaks were below $60 \mathrm{KHz}$. Average wind speed during acoustic surveys was $8.7 \mathrm{mpg}$, and average temperature was $71.5^{\circ} \mathrm{F}$. We did not find a significant correlation between the total number of species identified during surveys and temperature (Pearson correlation coefficient $=0.329, p=0.387$ ) or the total number of species identified during surveys and wind speed (Pearson correlation coefficient $=-0.115, p=0.769$ ).

\section{DISCUSSION}

In this study, we investigated and successfully utilized several non-invasive, affordable smartphone enabled applications and devices to study bats. While no bat individuals occupied deployed bat boxes during the course of our research study, our hypothesis was support as we successfully detected 5 species of bats using the Wildlife Acoustics Echo Meter Touch 2. We expect bat boxes require longer monitoring periods than 2 seasons (April to October 2018), as often it may take several years for bats to occupy any individual bat box (Tuttle et al., 2013). Moreover, two additional non-invasive methods were successfully utilized supporting our hypothesis; a WIFI smartphone endoscope to check for bat occupancy, and WIFI smartphone enabled temperature and light data loggers to record internal bat box temperature and luminosity. We found the bat box deployed in full sun showed significantly higher amounts of natural light, indicating the placement of this bat box may more closely mimic ideal natural roosts (Tuttle et al., 2013). While we noted some slight variation, mean temperature of bat boxes was similar in both partial and full sun bat boxes (BB1 and BB2), as average temperature was likely influenced by ambient temperatures. Potential source of error for the data logger could include ideal location inside the bat box, as we attached data loggers to the bottom entrance. Future studies could vary placement of data loggers further inside the bat box to test variation in temperature within each bat box chamber. In addition, if bat boxes are occupied, the internal temperature may be affected by the number of bats generating heat. Subsequently, if bat boxes are occupied 
researchers should exercise caution when inserting the endoscope into the bat box as to not disturb bats. Additional research of occupied bat boxes could document emergence time of individual bats exiting the boxes for feeding using the Echo Meter Touch 2 .

The most frequently detected bat species in our study, the big brown bat, is capable of detecting insects as far away as five meters (Kick and Simmons, 1984), and is resistant to white nose syndrome (Frank et al., 2014). This may indicate the most common species inhabiting semi-urban and semi-natural areas is either naturally common in population size or is successfully outcompeting other native North Carolina Piedmont bat species possibly due to disease resistance. Alternatively, E. fuscus is a species which is able to thrive in urban areas (Geggie and Fenton, 1985), similar to our study area and more likely forms maternal roost in buildings over bat boxes (Agosta, 2002). The Mexican free-tailed bat, has more recently expanded its geographic range into North Carolina and is now established in year-round colonies, often inhabiting buildings and bat boxes (McCracken et al., 2018). Other species we detected, the hoary bat, has been observed in similar habitats, even showing interspecific aggression behavior towards the Silver-haired bat which was another species detected (Brokaw et al., 2016). Lastly, the Northern yellow bat is among the largest of North Carolina Piedmont area bats commonly documented foraging in golf courses and edges of lakes and forests, but can be negatively affected by increases in agriculture of development (Barbour and Davis, 1969; Neece et al., 2018).

While our study focused on non-invasive monitoring methods for bats, future work on our study site should focus on confirmation of bat identification by monitoring both man-made structures and natural roost sites used at our study area and possibly capturing individual bats. However, this type of research requires following both state and federal permits, and obtaining rabies vaccination by local health centers for handling of any individual bats, so both citizen scientists and researchers should follow appropriate guidelines for animal care and use involving research on bats. Possible sources of error in this study include issues pertaining to misidentification of species based on the accuracy, echolocation call parameters, quality of calls (ambient noise or increased distance of observer recording to bat in flight), and assumptions of the automated identifier used (Wildlife Acoustics Echo Meter Touch 2 application). We recommend the use of additional software to analyze in more detail echolocation call parameters and confirm species identification. In addition, we only recorded calls 30 minutes before and after sunset, indicating that possibly other species may be present at different times or that some species of bats may alter their emergence and foraging times based on season, temperature, and other factors (Thomas and Jacobs, 2013).

Clearly, smartphone technology has a great deal of potential for collecting a greater volume of baseline data, not just in bat species observations, but also for collecting other environmental data. For example, non-invasively checking natural cavities for insects, or assessing occupancy of bird nesting boxes, as well as many other applications for acoustic surveying and determining species presence. Citizen scientists and undergraduate researchers at universities should incorporate the smartphone technologies we assessed in our study into their own research or even for outreach science programs, for which we have used the Echo Meter Touch 2 on several occasions as a teaching tool for undergraduate biology majors and for the local community at large. Moreover, continued development of smartphone technology for monitoring species can allow citizen science communities to function much as their own research institutions collecting important baseline data which they can share with local state conservation agencies (August et al., 2015). Therefore, we propose further research using affordable smartphone enabled technologies which can be incorporated into testing many future scientific hypotheses in wildlife biology.

\section{ACKNOWLEDGMENTS}

The authors would like to acknowledge the Wingate Wildlife Club, Mark Rollins, and Brandon Wilson for helping with bat box deployment and painting. Wingate Biology Department provided funding for this undergraduate directed research project. As no animals were handled in this study, authors received approval from the Wingate Research Review Board.

\section{REFERENCES}

AccuWeather. (n.d.). Retrieved November 1, 2018, from https://www.accuweather.com.

Agosta, S. J. (2002). Habitat use, diet and roost selection by the Big Brown Bat (Eptesicus fuscus) in North America: a case for conserving an abundant species. Mammal Review, 32(3), 179-198, available:10.1046/j.13652907.2002.00103.x.

August, T., Harvey, M., Lightfoot, P., Kilbey, D., Papadopoulos, T., and Jepson, P. (2015). Emerging technologies for biological recording. Biological Journal of the Linnean Society, 115, 731-749.

Barbour, R. W., Davis, W. D. (1969). Bats of America. Lexington, Kentucky: University of Kentucky Press.

Boyles, J. G., Cryan, P. M., McCracken, G. G., and Kunz, T. H. (2011). Economic importance of bats in agriculture. Science, 332(6025), 41-42, available: 10.1126/science. 1201366 .

Brokaw, A. F., Clerc, J., and Weller, T. (2016). Another account of interspecific aggression involving a Hoary bat (Lasiurus cinereus). Northwestern Naturalist, 97(2), 130-134, available: 10.1898/NWN15-27.1.

Caldwell, K., Sherrill, B., Medford, A., Weeks, and Weeks, K. (2017). Bats of North Carolina. North Carolina Wildlife Resources Commission, available: www.ncwildlife.org/Portals/0/Conserving/documents/Profiles/Bats_Species_Profile.pdf.

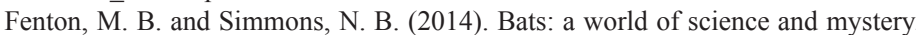
Chicago, Illinois: University of Chicago Press.

Frank, C. L, Michalski, A. McDonough, A. A, Rahimian, M., Rudd, R. J., and Herzog, C. (2014). The resistance of a north American bat species (Eptesicus fuscus) to White-Nose syndrome (WNS). PLoS One, 9(12), e113958, available: 10.1371/journal.pone.0113958.

Frigerio, D., Pipek, P., Kimmig, S., Winter, S., Melzheimer, J., Diblikova, L., Wachter, B., and Richter, A. (2018). Citizen science and wildlife biology: Synergies and challenges. Ethology, 124(6), 365-377, available: 10.1111/ eth. 12746

Geggie, J. F. and Fenton, M. B. (1985). A comparison of foraging by Eptesicus fuscus (Chiroptera:Vespertilionidae) in urban and rural environments. Canadian Journal of Zoology, 63(2), 263-266, available: 10.1139/z85-040.

Graeter, G. J., Diggins, C. A., Weeks, K. C., and Clark, M. K. (2015). New distribution records for bats in northwestern North Carolina. Southeastern Naturalist, 14(1), 98-105.

Griffiths, S. R., Bender, R., Godinho, L. N., Lentini, P. E., Lumsden, L. F., and Rob- 
ert, K. A. (2017). Bat boxes are not a silver bullet conservation tool. Mammal Review, 47(4), 261-265, available: 10.1111/mam.12097.

Gutowsky, L. F. G., Gobin, J., Burnett, N. J., Chapman, J. M, Stoot, L. J., and Bliss, S. (2013). Smartphones and digital tablets: emerging tools for fisheries professionals. Fisheries, 38(10), 455-461.

Jones, G., Jacobs, D. S., Kunz, T. H., Willig, M. R., and Racey, P. A. (2009). Carpe noctem: the importance of bats as bioindicators. Endangered Species Research, 8, 93-115, available 10.3354/esr00182.

Jones, K. E., Mickleburgh, S. P., Sechrest, W., and Walsh, A. L. (2010). Global overview of the conservation of island bats: importance, challenges, and opportunities, In T. H. Fleming and P. A. Racey (Eds.), Island Bats Evolution, Ecology, and Conservation (pp. 496-530). Chicago, Illinois: University of Chicago Press, North America.

Kick, S. A. and Simmons, J. A. (1984). Automatic gain control in the bat's sonar receiver and the neuroethology of echolocation. Journal of Neuroscience, 4, 2725-2737.

Kunz, T. H. and Lumsded, L. F. (2003). Ecology of cavity and foliage roosting bats, In T. H. Kunz and M. B. Fenton (Eds.), Bat Ecology (pp. 3-69). Chicago, Illinois: University of Chicago Press, North America.

McCracken, G. F., Bernard, R. F., Gamba-Rios, M., Wolfe, R., Krauel, J. J., Jones, D. N., Russell, A. L., and Brown, V. A. (2018). Rapid expansion of the Brazilian free-tailed bat in the southeastern United States, 2008-2016. Journal of Mammalogy, 99(2), 1-9, available 10.1093/jmammal/gyx188.

Neece, B. D., Loeb, S. C., and Jachowski, D. S. (2018). Variation in regional and landscape effects on occupancy of temperate bats in the southeastern US. PLoS ONE 13(11), e0206857, available 10.1371/journal.pone.0296857.

Nugent, J. (2018). iNaturalist: Citizen science for 21 st-century naturalist. Science Scope, 41(7), 12-13.

Parusnath, S., Little, I. T., Cunningham, M. J., Jansen, R., Alexander, G. J. (2017). The desolation of Smaug: The human-driven decline of the Sungazer lizard (Smaug giganteus). Journal for Nature Conservation, 36, 48-57, available 10.1016/j.jnc.2017.02.002

Rueegger, N., Goldingay, R. L., Law, B., and Gonsalves, L. (2018). Limited use of bat boxes in a rural landscape: implications for offsetting the clearing of hollow-bearing trees. Restoration Ecology, December 2018, available 10.1111/ rec. 12919

Schimpp, S. A. and Kalcounis-Rueppell, M. C. (2018). Determining species specific nightly bat activity in sites with varying urban intensity. Urban Ecosystems, 21(3), 541-550, available 10.1007/s11252-019-0737-y.

Stitt, J. M., Svancara, L. K., Vierling, L. A., and Vierling, K. T. (2019). Smartphone LIDAR can measure tree cavity dimensions for wildlife studies. Wildlife Society Bulletin, 43(1), 159-166, available 10.1002/wsb.949.

Thomas, A. J. and Jacobs, D. S. (2013). Factors influencing the emergence times of sympatric insectivorous bat species. Acta Chiropteroligica, 15(1) 121-132, available 10.3161/150811013X667920.

Turner, G. G., Reeder, D. M., and Coleman, J. T. H. (2011). A five-year assessment of mortality and geographic spread of white-nose syndrome in North American bats and a look into the future. Bat Research News, 52, 13-27.

Tuttle, M. D., Kiser, M., and Kiser, S. (2013). The Bat House Builder's Handbook. Austin, TX: University of Texas Press.

White, E. P. (2004). Factors affecting bat house occupancy in Colorado. The Southwestern Naturalist, 49(3), 344-340.

Williams, K., Mies, R., Stokes, D., and Stokes, L. (2002). Beginner's guide to bats. New York, NY. Little, Brown and Company Press.

Willie, M., Rowland, E., and Mullaley, A. (2018). First documentation of roost use by little brown myotis (Myotis lucifugus) on the North coast of British Columbia. Northwestern Naturalist, 99, 187-196. 